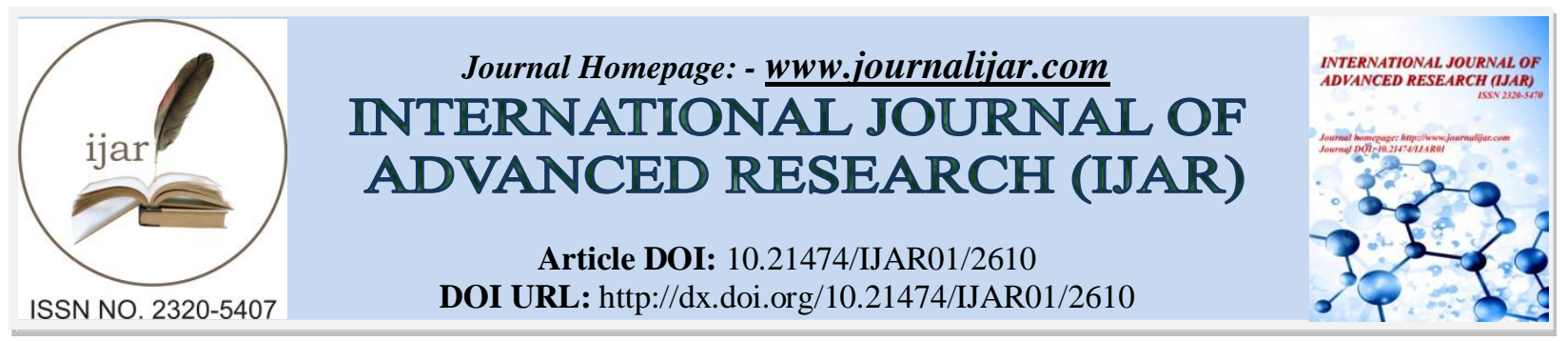

RESEARCH ARTICLE

\title{
MEDIASTINAL TUMORS: CLINICOPATHOLOGICAL ANALYSIS AND SURGICAL MANAGEMENT - A TEN YEAR STUDY FROM A TERTIARY CARE CENTRE.
}

\author{
Abid Manzoor Wani, Nasir Ud Din Wani, Mir Mudasir Sidiq, Abdul Gani Ahangar, Ghulam Nabi Lone and \\ Parveen Shah.
}

\section{Manuscript Info}

Abstract

Manuscript History

Received: 30 October 2016

Final Accepted: 29 November 2016

Published: December 2016

Copy Right, IJAR, 2016,. All rights reserved.

\section{Introduction:-}

Tumors of mediastinum represent a wide diversity of disease status. The location and composition of mass is critical to narrowing the differential diagnosis ${ }^{1}$. The presentation of mediastinal tumors depends upon the location, size, and invasiveness, degree of compression and endocrine effect of tumor ${ }^{2}$. The diagnosis of mediastinal mass is an extremely challenging job. Careful history, physical examination combined with imaging and biochemical markers are useful for diagnosis.

\section{Material and Methods:-}

This study was conducted from April 2003 to October 2013 and a total of 98 patients with mediastinal mass lesions who have been operated in the department of Cardiovascular and Thoracic surgery in Sher-i-Kashmir Institute of Medical Sciences, Srinagar during this time period were included in this study.

A comprehensive and detailed proforma was filled up for every patient. Detailed history and clinical examination was performed in every patient. Baseline hematological and biochemical investigations, chest $\mathrm{x}$-rays, and contrast enhanced computerized tomography of chest was performed in every patient. Further investigations were suggested by the individual clinical profile of the patient. MRI was performed in patients where vascular lesion or spinal cord involvement was suspected. Tumor marker levels were performed according to clinical profile. USG or CT guided biopsy was performed if there was no contraindication for the procedure. Informed consent was taken. Patients were operated through Sternotomy / Thoracotomy / Cervical approach depending upon the location of tumor. Surgical staging was done during the operating procedure. Specimens were sent for histopathology and marker studies. All patients were examined daily for any post-operative complications. Hospital stay was noted. Medical oncology/radiation oncology consultation was considered in postoperative period. Post operative chest x-ray and chest computerized tomography were done on follow up.

All the data were recorded in a pre-structured proforma and was presented by percentage and appropriate statistical charts. 


\section{Results:-}

The mean age of presentation of our patients of mediastinal mass lesion was 35.4 years with a range of 1-70 years and most of patients were in the age group of 20-40 years. Male to female ratio was 1.3:1 and most of patients belonged to rural areas (Table 1).

Although many patients presented with multiple symptom complexes but cough was most common presenting symptom $(55.10 \%)$ followed by chest pain $(31.63 \%)$ and duration of symptoms varied from 1-18 months. Mediastinal mass was an incidental finding in 20 patients (Table 2).

Anterior mediastinum was the commonest site of mass lesion (60.2\%) followed by posterior $(22.4 \%)$ and middle mediastinum (17.3\%). Thymoma was the commonest diagnosis $(30.06 \%)$ and more common in females with female to male ratio of 2.3:1. 68.3\% of mass lesions were benign and $31.6 \%$ were malignant (Table 3).

The commonest surgical approach was thoracotomy however sternotomy was required in good number of patients for thymic excision or excision of larger masses (Table 4). Complete excision was carried out in 61 (62.2\%) patients, whereas only biopsy and debulking was possible in 37 (37.7\%). Most of the patients had uneventful postoperative course. However, complications occurred in 14 patients, commonest being wound infection (8 patients) followed by respiratory tract infection (Table 5). One patient required prolonged postoperative ventilation because of phrenic nerve palsy. Two patients died: one because of sternal dehiscence and other due to myasthenia crisis. Hospital stay varied from 3-22 days with most of the patients staying for 6-10 days (Table 6)

\section{Discussion:-}

In our study male to female ratio was 1.3:1 which was in concordance with studies conducted by Bastos $\mathrm{P}$ et al ${ }^{3}$ and Adegboye VO et $\mathrm{al}^{4}$. Most common symptoms were cough (46.9\%) and chest pain (26.53\%) which were comparable with studies of Cemil Deniz Yorgancilar et $\mathrm{al}^{5}$. They reported cough in $34 \%$ of patients followed by chest pain $(15 \%)$ and dyspnea(11\%).

Bastos $\mathrm{P}$ et $\mathrm{al}^{3}$ in their study observed anterior mediastinum the most common site of tumor (58\%) and Davis RD et $\mathrm{al}^{6}$ found that $54 \%, 26 \%$ and $20 \%$ of mass lesions were located in anterosuperior, posterior and middle mediastinum, respectively. Similarly in our study most common site of mass lesion was anterior mediastinum $(60.20 \%)$ followed by posterior $(22.45 \%)$ and middle mediastinum $(17.35 \%)$.

In our study thymic neoplasm was the commonest diagnosis (30.6\%) followed by neurogenic tumors (18.4\%) and in thymoma female to male ratio was $2.3: 1$. Thymic tumors were the commonest diagnosis $(31 \%)$ followed by lymphoma (22\%) and neurogenic tumors (16\%) in study by Bastos $\mathrm{P} \mathrm{et} \mathrm{al}^{3}$. Similarly, Takeda $\mathrm{S} \mathrm{et} \mathrm{al}^{7}$ reported thymic tumors in $36 \%$ patients. Katiach $\mathrm{H} \mathrm{et} \mathrm{al}^{8}$ reported that $76.47 \%$ of patients with thymomas were females. Germ cell tumors were present in $11(11.2 \%)$ patients which was comparable with study of Chandra P Shirivastava et al. Lymphoma was present in $16(16.3 \%)$ patients with Hodgkin's lymphoma in $62.5 \%$ and NonHodgkin's type in $37.5 \%$. Anterior mediastinum was the site for $68.7 \%$ of lymphomas. Strickler JG et al ${ }^{9}$ also found Hodgkin's disease as most common lymphoma in mediastinum.

Because of the location of the mediastinal tumors which are surrounded by vital structures and embedded in bony cage, exploratory thoracotomy is widely used for taking a biopsy and establishing the diagnosis in inoperable cases. However, if these tumors are found operable on table, excision can be performed through the same approach in the same setting. It is evident from our study that this can be done with low morbidity and mortality. 


\section{Bibliography:-}

1. Beau V. Duwe, Daniel H. Sterman and Ali I. Musani. Tumors of the mediastinum. Chest 2005; 128(4):28932909

2. Chandra P Shirivastava, Sanjeev Devgarha and Vikas Ahlawat. Mediastinal tumors: a clinicopathological analysis. Asain Cardiovasc Thorac Ann 2006; 14: 211-218

3. Bastos P, Magalhaes A, Fernandes G, Cruz MR, Saleiro S, Goncalves L, Pinon M. Primary cysts and tumors of the mediastinum. Rev Port Pneumol. 2007; 13(5): 659-73

4. Adegboye VO, Ogunseyinde AO, Obajimi MO, Ogunbiyi O, Brimmo AI, Adebo OA. Presentation of primary mediastinal masses in Ibadan. East Afr Med J. 2003 Sep; 80 (9): 234-9

5. Yorgancilar CD, Karakurt O, Tilkan OK, Demircan S. Our diagnostic and therapeutic surgical approaches to mediastinal masses. J Int Dent Med Res. 2010; 3(2):82-87

6. Davis RD, Oldham HN, Sabiston DC. Primary cysts and neoplasms of mediastinum: recent changes in clinical presentation, methods of diagnosis, management, and results. Ann Thorac Surg. 1987 Sep; 44(3): 229-37

7. Takeda S, Miyoshi S, Akashi A, Ohta M, Minami M, Okumura M, Masaoka A, Matsuda H. Clinical spectrum of primary mediastinal tumors: A comparison of adult and pediatric populations at a single Japanese institution. J Surg Oncol. 2003 May; 83(1): 24-30

8. Kattach H, Anastasiadis K, Cleuziou J, Buckley C, Shine B, Pillai R, Ratnatunga C. Trassternal thymectomy for myasthenia gravis: surgical outcome. Ann Thrac Surg. 2006 Jan; 81(1): 305-8

9. Strickler JG, Kurtin P. Mediastinal lymphomas. Semin Diagn Pathol. 1991; 8: 2-13 